\title{
Action Design Ethnographic Research (ADER): Vested Interest Networks and ICT Networks in Service Delivery of Land Records in Bangladesh
}

\author{
M. Shahanoor Alam ${ }^{1}$, Laurence Brooks ${ }^{1, *}$, and N.I. Khan ${ }^{2}$ \\ ${ }^{1}$ Department of Information Systems and Computing, Brunel University, \\ London, UB8 3PH, UK \\ ${ }^{2}$ National Project Director, Access to Information (A2I), Office of the Prime Minister, \\ Tejgaon, Dhaka, \& Secretary, Ministry of ICT, Bangladesh \\ \{Muhammad.Alam, Laurence.Brooks\} @brunel.ac.uk
}

\begin{abstract}
Identifying rigorous and relevant research methods has for a long time been a challenge in IS research. This is amplified in developing countries, where understanding the context is key. This paper presents an Action Design Research based approach, incorporating ethnography, which aims to provide a more authentic and relevant analysis. The Action Design Ethnographic Research (ADER) method is illustrated through the case of ICTs and land records management in Bangladesh. The findings show that where ICTs have been introduced so far, they do not clearly relate to the specific organizational context and service delivery processes. Furthermore, they fail to recognize the role of what is termed here 'vested interest networks', which sit outside the formal processes, but are key to their effective functioning. This paper suggests ADER has the potential to enable the development of more contextually contingent, authentic and hence useful ICTs, especially in the developing countries context.
\end{abstract}

Keywords: Action Research, Design Research, Action Design Research, Action Design Ethnographic Research, land records management, Bangladesh.

\section{Introduction}

Studying ICTs in developing countries, a complex sub-field of IS discipline, requires rigorous research methods because usual quantitative analyses and descriptive methods fail to capture sufficient insights and therefore to solve current problems [13]. Empirical and interventional methods notably Action Research (AR), Design Research (DR) and Action Design Research (ADR) have the potential to ensure rigorous research through unfolding insights and solving immediate problems. Amongst these, ADR is the youngest and most promising method, developed within the IS discipline in order to achieve rigor and relevance. ADR aims to solve immediate problems through concurrent and authentic evaluation. Thus, ADR unfolds

\footnotetext{
* Corresponding author.
} 
significant features as a rigorous research method for studying ICTs in developing countries. However, it has been developed in the context of developed countries; consequently ADR says little about how to reach insights in the study of ICTs in the context of developing countries. Thus, studying ICTs in complex contexts of developing countries requires an additional lens alongside ADR to uncover the subtle contexts and to conduct objective and concurrent evaluation. Therefore, the ethnographic perspective, a basket of research tools looks to have potential value in IS research for eliciting insights and conducting objective evaluations [4, 5]. Consistent with these, this paper intends to apply ADR in the context of developing countries along with ethnographic perspectives that can be termed as Action Design Ethnographic Research (ADER), an extended variant of ADR.

The diverse interests and multi-disciplinary nature of Information Systems (IS) research has generated a longstanding need for rigorous research methods to study organization and human actors who shape ICTs [6]. To this end, attempts have been made by IS professionals and practitioners [7, 8]. Recently, ADR has brought DR and AR under one umbrella through framing DR [7] with the essence of AR [8] to ensure rigor and relevance and to avoid overlapping [9]. Uniquely, ADR does not separate design and evaluation sequentially like the 'stage-gate sequential model' [9].

However, implementation of ICTs has been shaped by formal and informal as well as hidden subtle contexts in developing countries [1,3]. The ethnographic perspective is reputed to be able to apply its basket of tools and techniques to elicit insights into contexts under study. This pioneer study applies ADR in a complex context i.e., service delivery of land records in Bangladesh where informal and hidden practices strongly prevail; we incorporate ethnographic perspectives into the ADR framework. This does not require any extra steps, but helps to uncover hidden contexts and contribute to the ADR process. Therefore, this paper presents ADER as an extended variant of ADR.

Due to over population, land is an extremely scarce resource in Bangladesh. It has a total of 14.4 million hectares of land for its 160 million people; $60 \%$ of the total labour force is deployed in agriculture, which contributes $55 \%$ of the total GDP [10]. Land records are inevitably needed for legal, financial and welfare services, development planning, transfer of land ownership, determination of ownership and size of land parcels and resolution of land litigations. Thus, land records are a basic service delivery.

Bangladesh gained independence in 1971, following both British India rule (17571947) and Pakistan rule (1947-1971). Its land records system was originally developed by the Colonial government in the 1920s, revised in the 1950s (under the Pakistan administration) and finally another version has been produced since the 1970s. Therefore, a land parcel has three versions of land records and legally all these are functioning. It makes the land records system archaic dilapidated and complex. Furthermore, service delivery of land records follows a rigid bureaucratic process. All parties involved have developed rampant corruption and rent seeking practices in this type of service delivery in Bangladesh, termed as 'vested interests' [11]. Consequently this service has been ranked top for corruption and become a major source of litigation and public suffering. To address these problems, the incumbent government has launched the project 'Access to Information' (A2I). A2I aims to develop ICT networks to bring this service delivery to the citizens' doorstep. It has established a total 4501 
telecentres, known as Union Information Service Centres (UISC) in the rural areas and a web portal and an e-service centre in each district throughout the country, from November 2010. Since its inception, A2I has been facing problems with implementing ICT networks in this service area. Thus, since December 2011, the research team, collaborating with A2I, has been working to address the problems in implementing ICT networks in land records management, using ADER.

\section{$2 \quad$ Methodology}

The ADER team comprises three members combining IS professionals and practitioners. The first author played a dual role: formerly an employee in this service delivery and currently a doctoral student. The second author/academic researcher coordinates the practitioners and professionals. The third author is a practitioner involved in A2I management and served in land records related services for a total of ten years. Initially, the team chose ADR to address the problems in implementing ICT networks in this service delivery process, instead of AR or DR. Since the team has the opportunity to work with the A2I service delivery provider and telecentres, there is the opportunity to build and redesign this service delivery processing ADER. Further, it provides concurrent and objective evaluation of both the initially designed and ADER designed ICTs networks.

ADR outlines two streams of building, intervention and evaluation. One is ICT dominant and the other is organisation dominant [9]. The study has chosen an organisation dominant stream of ADR because in this service delivery process the role of ICT is minimal compared with the role of the organization as an ensemble artefact. While conducting ADR, the study faced difficulties with identifying the reasons for failure in implementing ICT networks using only the usual questionnaire survey, observation and interviews; instead it adopted an ethnographic perspective to investigate the underlying causes. Ethnographic perspectives rely on a number tools and techniques whereby the insider and outsider view are prominent. The ADER team applies an insider (native) point-of-view from the perspectives of service delivery staff and citizens through participating in the real contexts via participant observation, role playing, building rapport, applying storytelling and life history techniques. It applies an outsider view (researcher) to build rationalistic achievable processes and networks based on the practices, contexts and capacities from all the stages of ADR. The heterogeneity of the ADER team as native and non-native professionals and practitioners has given the opportunity to employ ethnographic perspectives in the ADR process.

ADR's focus is on situated learning. Therefore, this study focuses on a project in a district of Bangladesh called Shopnapur (not its real name) and its sub-district Rooppur (not its real name). The sample includes the Deputy Commissioner's Office, the e-Service Centre, the District Records Room (DRR) located in the district headquarters and the five UISCs of the sub-district. Since both ADR and ethnographic perspectives require long term commitment and involvement, the study involved long term involvement with the service providers, service delivery staff, citizens and many other actors in the ICT networks and vested interest networks. Consequently, a wide range of methods, techniques and tools have been used for data collection; these 
include observation, participant observation, ethnographic interviews, document analysis and focus group discussions. Data is interpreted is via thematic analysis within an interpretive perspective using an Actor Network Theory (ANT) theoretical lens.

\section{Literature}

IS studies in developing countries (DCs) focus on development, implementation and use of ICT artefacts and tracing the roots of the obstacle behaviour and processes of implementing ICTs [1, 6, 12]. Since ICTs alone do not change the existing organizational practices, network and settings there is a need for studies to examine ICTs in organisational contexts [5]. Users do not accept ICTs as it is designed, they reshape it through practices and contexts. Thus, understanding the implementation of ICTs in service delivery is challenging for its complex interrelationships with socioeconomic contexts. Moreover, implementation of ICTs in service delivery of land records is difficult because of the existence of various interests [13]. It is influenced by social, cultural and bureaucratic practices and ICT fails if its design ignores them [14]. Similarly, Sahay and Avgerou [15] identified the domination of existing networks as a bar to implementing ICTs in DCs. Thus, implementation of ICTs in service delivery of land records is not merely a technical issue but also rests on organizational contexts, actors and networks.

ICTs can be used to improve service delivery [16], but it involves many phases, processes, actors, roles and practices. As a potential theoretical framework to support this, ANT is a powerful lens that focuses on technology and actors' complex relationships through examining networks between people, machines and noncorporeal artefacts collectively [17]. Further, it seeks intertwined relationships between human actors, agency and ICTs for better understanding the embedded rules, resources, behaviours and human actors [18].

ANT explains the world as the sum of networks which include humans, things, ideas, and concepts as 'actors' in the networks [19, 20]. It provides a substantial realistic framework to reveal organizational learning in broadly four steps problematisation, interessement, enrolment and mobilisation all achieved through translation. Problematisation develops ideas or artefacts to address a specific problem by focal actor(s) and makes it indispensable to the other actors through rhetorical means in terms of resources and capacities. This activity is called an obligatory passage point (OPP) [21]. Afterwards, the actors bargain with their interests (interessement), and make alliances through these interests and via concessions (enrolment). Actor-networks are the consequence of an alignment of diverse interests and the basis of enrolment of different actors into the network. Finally, actors become spokespersons in the networks and mobilise them [22].

This paper employs ANT as an analytical tool for understanding the actors and contexts relating to the ICT network with a view to guiding ADER (rather than contributing to the theory). 


\section{$4 \quad$ Action Design Research}

Organizational contexts inscribe development and use of IT artefacts that bring intended and unintended consequences [5, 9]. A complementarity between AR and DR is significant to design artefacts and redesign it through on-going use and evaluation. It helps to guide initial design and capture ensemble artefacts that emerge through use and redesign [9]. Consistent with these, ADR has been developed as a research method in which AR has a complimentary role in the DR process.

ADR aims to study ensemble artefacts in organisational contexts to "generate prescriptive design knowledge through building and evaluating ensemble IT artefacts in organizational settings" [9]. An ensemble IT artefact includes material and organizational features that are socially recognized as bundles of hardware and/or software [23]. Thus, designing an ensemble artefact requires interactions between technological and organizational dimensions [24] while organizational contexts, structures and networks play significant roles. Consequently, ensemble IT artefacts emerge from design, use and on-going refinement.

ADR is guided by theoretical precursors including the researcher's intent, the influence of users, as well as the context of on-going use [9]. ADR comprises four stages: 1) problem formulation, 2) building intervention and evaluation, 3) reflection and learning and 4) formalization of learning. These steps are guided by seven principles, shown in fig. 1:

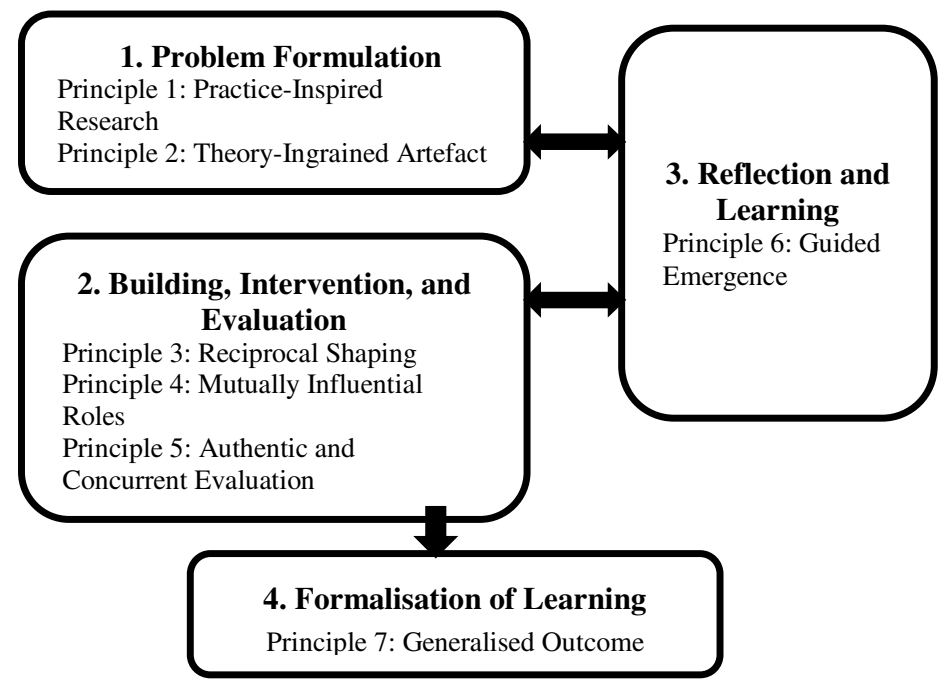

Fig. 1. Action Design Research (adopted from Sein et al., 2011)

\subsection{Problem Formulation}

ADR formulates problems in organizational contexts drawing from empirical cases or anticipated by researchers from practitioners, end-users, existing technologies and/or previous research [9]. It is shaped by research opportunities based on existing theories 
and technologies; involvement and commitment; research questions, and setting up roles and responsibilities. [9]. Thus, this stage follows two principles: practiceinspired research for contextualizing problems and solving a class problem; and theory-ingrained research focusing on ensemble artefacts that are informed by theories [9].

\subsection{Building, Intervention and Evaluation (BIE)}

This stage iteratively interweaves three core activities i.e., building IT artefacts; intervening organizational settings and evaluating it concurrently and objectively [9]. BIE has two distinct streams, IT dominant and organization dominant. Technological innovation requires IT dominant BIE where initially the role of practitioner is limited. On the other hand, organization dominant BIE is effective where the role of artefact is minimal and innovation relies on organizational intervention where practitioner and users play a potential role [9]. This stage includes three principles: reciprocal shaping between artefact and organizational contexts; mutual learning between researcher and practitioners and applying on-going authentic and concurrent evaluation [9].

\subsection{Reflection and Learning}

Reflection and learning refers to formulated problems, theoretical premises and emerged solution that contribute towards research process and knowledge [9]. It applies 'guided emergence' a principle containing two contrasting views 'guided' and 'emergence'. The former implies an external perspective i.e., guided intervention. The latter displays a sense of organic evolution which can be seen as an insider's perspective [9]. Both the perspectives help to reshape the designed artefact through on-going use in organizational context that derives from authentic and concurrent evaluation [25].

\subsection{Formalization of Learning}

This stage aims to formalize learning through generalizing the 'situated learning' [26]. The situated nature of ADR outcomes includes organizational change and implementation of an artefact. Thus, the researcher outlines accomplishments and describes organizational outcomes to formalize learning. It suggests three levels of outcomes: the problem instance; generalization from solution instances and derivation of design principles.

\subsection{ADER - A Need for an Ethnographic Perspective in ADR}

Ethnography refers to a sub-field of anthropology, a methodology, research perspectives that study human behaviour from social and cultural contexts. It is one of the most in-depth research methods and has contributed to the design and implementation of technology, informed by social and organizational contexts [27]. 
The ethnographic perspective employs a number tools i.e., living in the research field, inductive and participant observation, open ended interviews, emic (insider/native) and etic (outsider) views etc. Further, it applies inter-subjective ways of knowing through the 'reflexivity of actor' - the inquiring of researcher self and 'reflexivity of accounts' - ways of knowing the sense of clients or users which is beyond the self [28]. Moreover, it interprets the meaning of contexts rather than just description. Thus, ethnographic perspectives add potential value in empirical and interventional studies aimed at research problems, intervening process, evaluating objectively and generating knowledge.

Ethnographic perspectives play a pivotal role in the process of formulating problems through eliciting insights into the contexts, applying its tools and techniques. Further, insider and outsider perspectives help to develop a broader understanding of organizational intervention and building models and processes. Moreover, it helps reduce bias and tainted accounts through extensive observation and thick description for objective evaluation [29, 30]. Both ethnographic perspectives and thick description are interrelated, with thick description emerging from ethnographic techniques. Consequently, ethnographic perspectives can be seen as complementary to the ADR process. This study seeks to build a framework which incorporates ethnographic perspectives into ADR (see fig. 2).

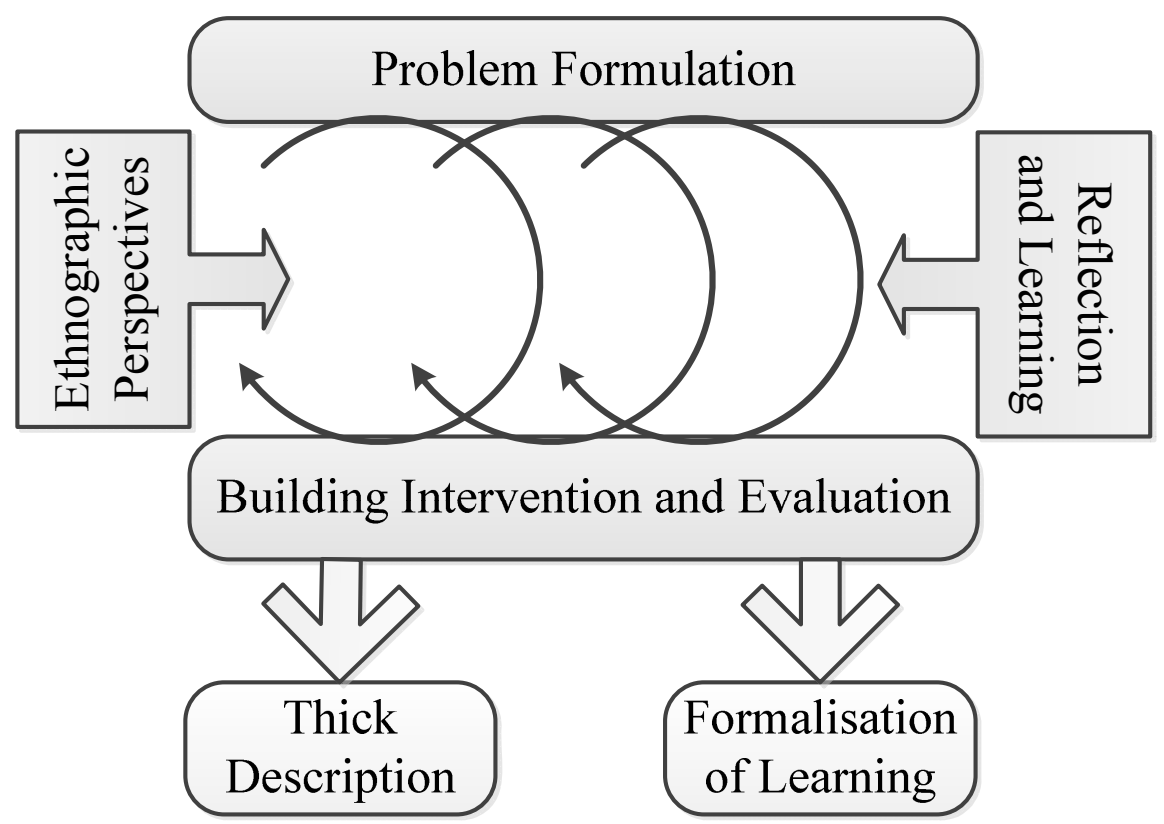

Fig. 2. Action Design Ethnographic Research (ADER) (adapted from Sein et al., 2011)

The proposed Action Design Ethnographic Research (ADER) framework aims to contribute to ADR in the following ways: 
1. Applying an ethnographic perspective bridge between stages. It reflects an iterative relationship from problem formulation to formalization of learning.

2. It helps to ensure objective evaluation and enhance authenticity through applying both insiders' and outsiders' perspectives.

3. It applies a number of perspectives, tools and techniques from ethnography known as thick description. Thus the ADER framework shows its potential to contribute to practice and knowledge

\section{$5 \quad$ Initial Design of ICT Networks in Organizational Contexts}

In Bangladesh, land records denote Records of Right (RoR) that contain land information - name of owner(s), parcel size, type, taxes and geographic boundary. RoR is recorded through a land cadastral ${ }^{1}$ survey. Usually land plots owned by a family are grouped into a RoR and a few hundred RoRs in a geographic area form a block. Service delivery of land records refer to issuing certified copies of RoR from the District Record Room (DRR) of the Deputy Commissioner's office.

The family based aggregated RoR system is complicated. For instance, a RoR contains names of land owners, ratios of ownership and land plots. Further, there are three types of RoRs that have been developed during three regimes (Colonial, Pakistan and Bangladesh). Consequently, land owners do not know accurately their RoR and Plot ID number and types due to the various types and aggregated nature of RoR. Therefore, it is difficult for most citizens to access service delivery by themselves, because applying for land records requires then to specify the block name, type of land record, RoR ID number and owner's name(s). Furthermore, calculating fee-stamps and folios is complicated and citizens cannot easily calculate this. Thus, over time, various networks have been developed: local, hidden, traditional, informal and organizational to mediate this service delivery. Since every network has vested interests, this paper treated them as vested interest networks (see fig. 3). The following section discusses the nature of the vested interest networks and how they reshaped the initial ICT network design.

\subsection{Vested Interest Networks}

A number of categories of actors and networks belong to the vested interest networks in this service delivery:

\subsubsection{Local Networks}

These include Deed-writers, Muhuris and Mobile Middlemen who are visible in rural localities and mediate service delivery for their clients and villagers. Deed-writers are practitioners writing land registration deeds. A land record is inevitably needed for the land registration deed, so they are involved in mediating this service delivery of their

\footnotetext{
${ }^{1}$ An official register containing information on the value, extent, and ownership of land for the purposes of taxation (Encarta dictionary).
} 
clients and villagers. 'Muhuris' are assistants to lawyers. Since $90 \%$ of the suits/cases relate to land records, Muhuris mediate and process land records for their clients and local citizens. Mobile Middleman is a hybrid of 'Muhuris' and 'Deed-writers'. They mediate this service delivery through mobile phone networks with the DRR staff that receive information from them by mobile phone and submit applications using the Web-portal and process their delivery. This network is preferable for rural citizens, as it avoids complex processes and significant travel.

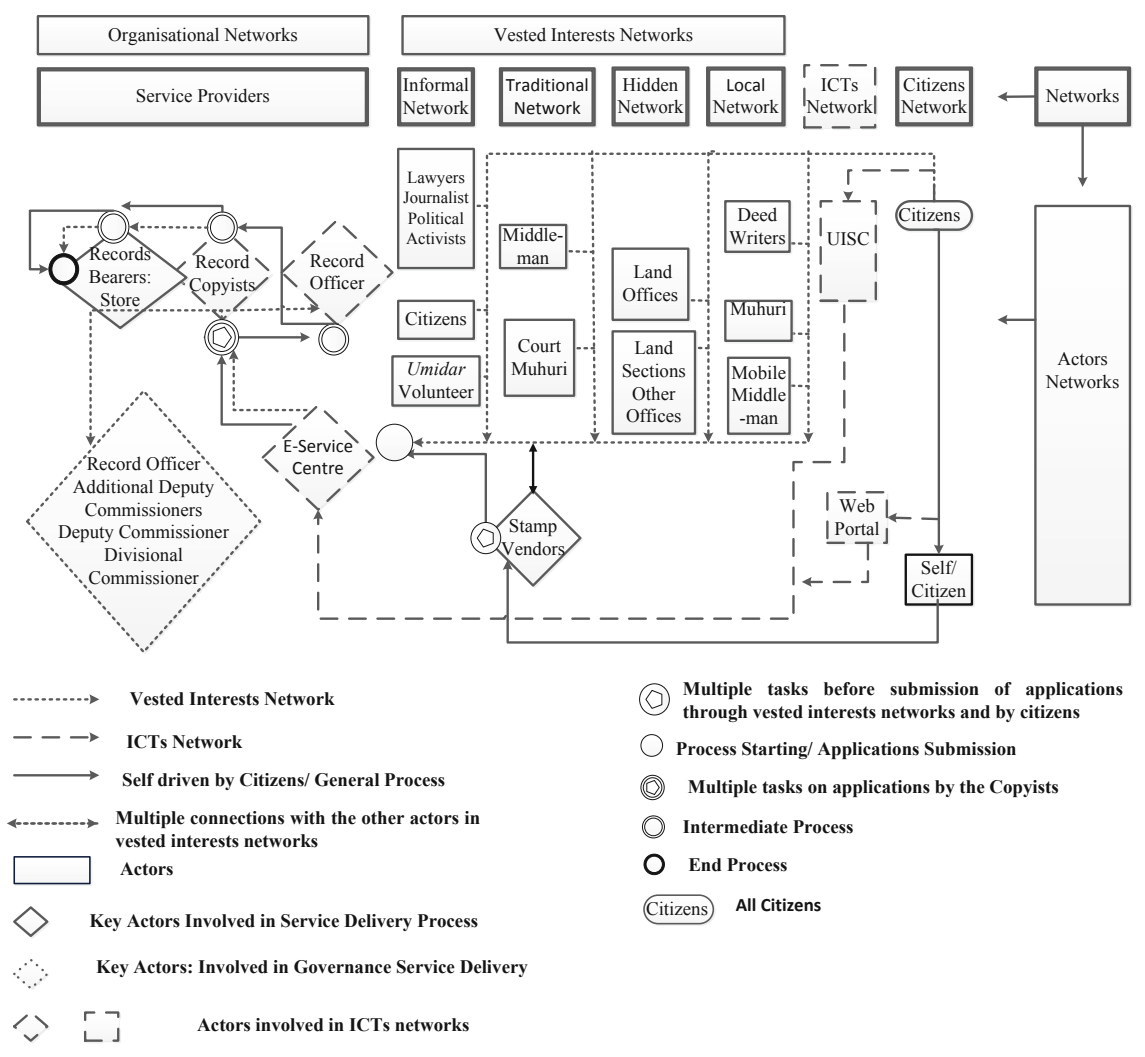

Fig. 3. The initial design of ICT networks and vested interest networks

\subsubsection{Hidden Networks}

Staff serving in land related section offices and other staff surrounding the DRR maintain hidden networks to mediate this service delivery. They are not visible on the spot. Citizens need land records to receive service delivery e.g., updating land records, collecting payment for land acquired and paying taxes. These networks mediate speedy and secure service delivery for their clients. 


\subsubsection{Traditional Networks}

Stamp-vendors, Court-muhuris and middlemen are traditional networks because they do this as a profession. Stamp-vendors are licensed to sell stamps and are required to pay fees for this service delivery. Court-muhuris, a sect of muhuris, who are licensed lawyers' assistants but work full-time to mediate this service delivery. Middlemen are either connected with political networks or staff networks. Their location is in front of the DRR. They have forms, stamps and folios for filing applications for this service delivery. Citizens who come to DRR for this service go them to complete the application process. If any record is damaged they know how to reproduce it, either legally or fraudulently.

\subsubsection{Informal Networks}

Lawyers, journalists and political activists are powerful actors in these networks. They use their professional identity to mediate this service delivery. The staff is also loyal to them because they are able to harm the vested interests of the staff. Umidar, the unpaid volunteers at DRR, mediate vested interests between the traditional networks and the staff. Therefore, every actor in the vested interested networks has their own vested interests and they are connected with the organizational networks

\subsection{Organizational Networks and Vested Interest Networks}

\subsubsection{DRR Staff Networks: Horizontal Interface}

The DRR staff includes Record Bearers, Copyists and Record Keepers. The Bearers sort and carry the land record registers from Store to Copyists. Copyists and Keepers both create certified copies of records. The Record Officer finally attests the processed records. The staff is horizontally connected with the vested interest networks.

Bearers maintain the closest network to records because they sort and carry them. The DRR has 10,000 record registers and they are stored about 300 feet away from the Copyists' Room. Bearers sort and carry daily about 200 registers. Since they have access to all records, they are connected with the vested interest networks which expedite sorting, carrying and supplying information about the availability of records.

The dilapidated condition of the records and the manual copying process creates a need for the Copyists-record network. About 35\% of records are damaged, but there is no list of them. Thus, it is at the Copyist's discretion as to whether he will process the certified copy or reject it on the grounds of damaged records. Thus, DRR staff ensures faster delivery through vested interest networks, while applying a high rate of rejection and delays in the case of ICT based applications.

\subsubsection{Service Delivery Staff Networks: Vertical Interface}

The DRR staff is vertically connected within organizational networks with the Officers involved in managing this service delivery (see fig. 3). Thus, staff distributes the benefits of vested interests to upper level officers, to secure their position. Thus, 
keeping the existing vested interest networks is a higher priority in the organizational networks than implementing the ICT networks.

\subsubsection{Service Delivery Process and Vested Interest Networks}

Filing an application for land records requires an application form, stamp-fees and folio-papers, which belong to the vested interest networks. Further, filling in an application form for land records is complicated. Thus, citizens are bound to enter into the vested interest networks. Further, since this service delivery works faster through vested interest networks, possibly within one or two working days, depending on networks and interests, whereas it takes several weeks through the ICT networks. Thus, the citizens already distrust the ICTs networks.

\subsection{The Initial Designs of ICT Networks and Underlying Contexts}

The A2I aims to bring service delivery of land records to the citizen's doorstep through ICT networks. IT artefacts were designed: three access points UISC, eService Centres and Web-portals and connecting them with the DRR to enable citizens' access to this service delivery. UISC is designed to submit online applications to DRR, but the organizational networks mandates that it also needs to submit a printed copy of the online submitted application via the postal service along with fee and folios. Their argument is that every application needs fee-stamps pasting on it and folio-papers. Since there is no option to submit fee-stamps and folio-papers with online applications, UISCs need to a send a printed copy of the online submitted application along with fee-stamps and folio papers. Consequently, it has created twice the tasks taking 15 days for an online application to reach the end of the process and another 15 days for this service to return to citizens (see fig.3). Thus, the ICT networks increases steps and processes. Further, the staff does not find vested interests in ICT networks thus there are a high number of rejections of applications coming from ICT networks.

The e-Service Centre is designed for the submission of online applications by citizens who are living in the district headquarters or coming to the DRR. The vested interest networks and the organizational networks reshaped this as a place for receiving paper-based application from vested interests networks; while the online entry is for the satisfaction of A2I, nothing else. As a result, the e-Service Centre created opportunities for the vested interest networks to prevail.

The Web-portal is designed to submit online applications for land records. Since only $0.35 \%$ of the population have Internet access this is unrealistic. However, it is also harnessed by the vested interest network. Since the copyists have good Internet connections and printers, they use it as an opportunity for submitting online applications via the Web-portal on behalf of vested interest networks. Further, it develops Mobile Middleman. Using the web-portal, the staff mediates service delivery of Mobile Middlemen networks. 
Though the initial design of ICT networks aimed to enhance citizens' access to this service delivery, it was overtaken by other actors i.e., the vested interest networks and organizational networks. Consequently, the ICT networks have been reshaped.

\section{ICT Networks in the ADER Context}

\subsection{Problem Formulation}

ADER brings forth insights into the context in implementing the initial design of ICT networks. During the design of the ICT networks by A2I, organizational contexts were not taken into account. Moreover, it was sequentially separated into building artefacts and implementation. As a result, the role of IT artefacts has been over emphasised while ignoring the contexts, capacities and role of the organisation. For instance, A2I designed three access points - UISC, e-Service Centre and Web-portal without contextualizing their role in local contexts and capacities. As a result, ICTs networks have neither achieved their goal nor addressed the underlying problems in this service delivery.

ADER formulates problems in the organizational contexts i.e., the prevailing vested interests networks; the relationships between vested interests networks and organizational networks and process of service delivery (see $5.1 \& 5.2$ ). Further, the existing legal infrastructure does not permit online payments. Moreover, the Internet users rarely require this service but it is essential to rural citizens.

ADER finds that with these contexts the initial IT dominant artefact (i.e., multiple access points in ICT networks) were not inscribed by the organization but appropriated by the vested interest networks. Further, the multiple access points and contexts do not allow for an obligatory passage point (OPP) and intervention. As a result, the ICT networks have been reshaped by the vested interest networks.

Therefore, ADER recognizes that it requires guided intervention to bridge the gap between the ICT networks and the organizational networks to set an OPP. Thus, with the view of guided interventions and setting OPP, ADER sees UISCs as a single access point and only allows online applications; no printed copy to prevent vested interest networks. Consequently, it has developed networks between citizens, UISCs, the DRR and the postal service through setting this OPP (See Fig.4).

To elicit these insights and formulate problems required setting long term interventions, building rapport with DRR staff and relevant actors, getting acquainted with the processes and the interests and seeing these from the local points of view (DRR staff, citizens and other actors).

\subsection{Building Intervention and Evaluation (BIE)}

Based on the problem formulations, ADER designed an ensemble IT artefact bringing ICTs and organizational contexts as mutually interdependent networks (See Fig.4). 

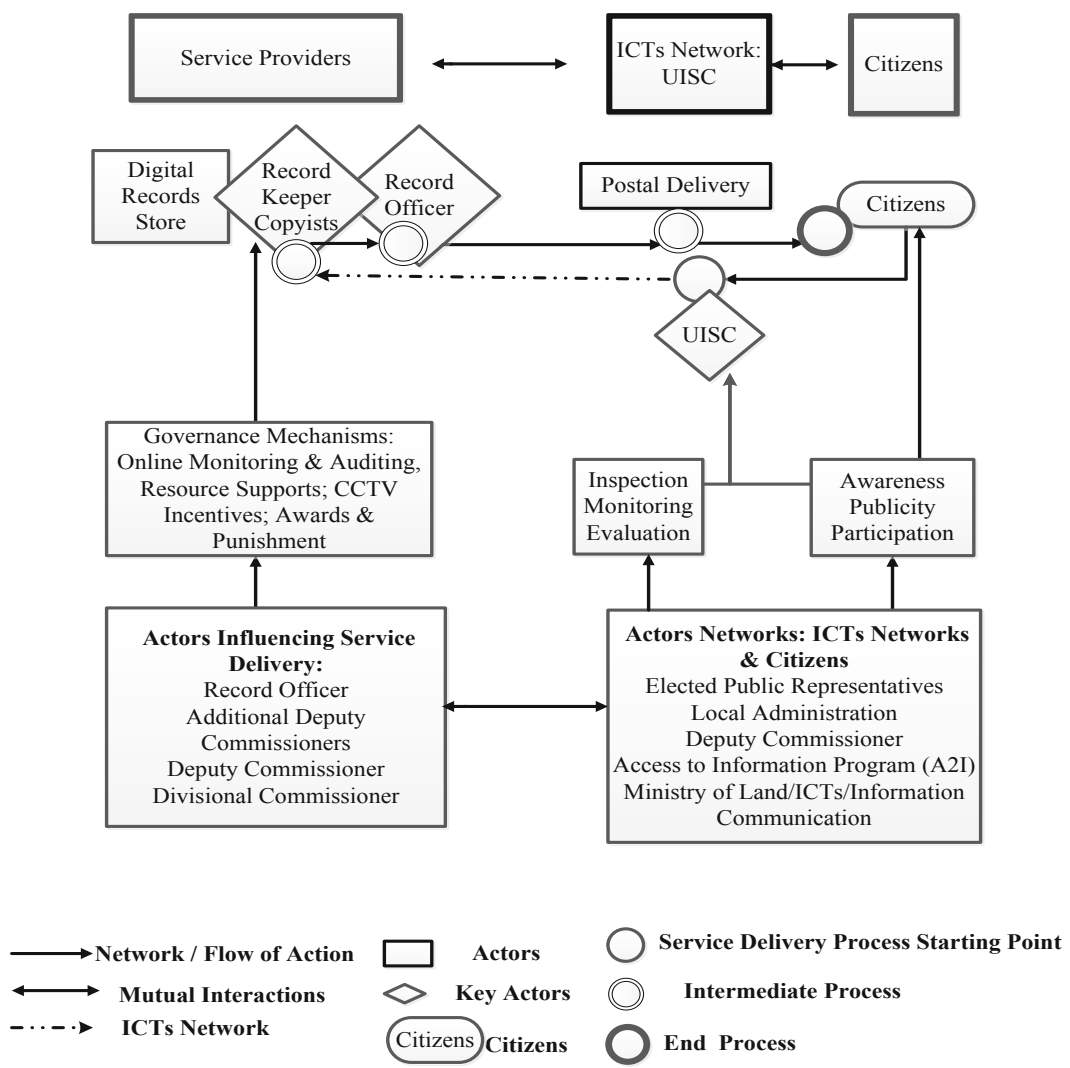

Fig. 4. ADER designed ICTs Networks

To inscribe the ICT networks within the organizational networks, ADER provide guidance for interventions with the existing capacities and technology. The DRR requires fee-stamps, folio-papers for each application and accounts for auditing. BIE seeks organizational capacities and practices, to address them. A guided intervention builds a bilateral network between UISCs and the DRR. Within this network, each UISC deposits fees and folios in advance for about 20 applications to the DRR. Upon receiving online applications from UISCs, the DRR deducts an amount of fees and folios. Further, the ADER team develops a register containing information for auditing fee-stamps including the application number, applicant name, name of UISC, amount of fee-stamp and folios, receiving date, copyist name and delivery date for each application. This makes it easy to track the applications and service delivery information for verification and evaluation.

The ADER designed ICT networks have been implementing in one Sub-district and it redesign is on-going. Evaluating the system after two months shows that a total of 30 applications have been received from five UISCs. Findings revealed that service delivery time has reduced from 20-30 days to 3-4 days at $2 / 3$ the cost of the previous 
process. Moreover, based on these results and on-going evaluation, this ADER designed ICT networks have been transferred to its neighbouring district.

Building organizational networks with ICT networks provides a common interessement between the actors of the ICT networks, DRR staff, citizens and UISC. Citizens benefitted from receiving the service without entering into any vested interest networks, UISCs benefitted with increased service delivery. The staff does not directly benefit. However, since they do not have options to provide service delivery to vested interest networks, they do serve the vested interests of organizational networks. Thus, three key actors are enrolled in the ICT networks.

Further, to avoid anticipated vested interest networks threats between UISC and the staff, the Postal Service has been enrolled to provide home delivery of this service to the recipients. Consequently, the vested interest networks find no way to access the ICT networks. Further, the mobilization process engages a number of organizational actors to support the ICTs networks through monitoring, coordinating and building citizens awareness (see Fig.4). The Ministry of Land has provided A2I with a 500 million Bangladeshi Taka (about $\$ 6.1$ million) fund to computerize all existing records. This would further support the success of the ADER designed ICT networks.

The ethnographic perspectives play a potential role as a link between formulated problems and BIE. Applying outsiders' view i.e., the researchers' perspectives, knowledge and skills, they intervene and develop bilateral networks between DRR and UISC to overcome the problem of sending printed copies of the online submitted application, and reduce steps and time for providing this service delivery through ICT networks.

\subsection{Critical Reflection and Learning}

This case shows how the complex organizational contexts, organizational networks and vested interests networks collectively reshaped the IT artefacts. The initially artefact designs were IT dominant and incompatible with the organizational context, and failed to achieve its goal. Moreover, it has been inscribed by the vested interested networks. This ADER approach has redesigned the artefacts with a guided intervention contextualizing the legal, organizational and social infrastructures.

The insiders' view is used to understand the organic, emerging and on-going use of initial artefacts. It is worth noting that the staff developed mobile-middleman networks using the web-portal. Thus applying insiders' view gives valuable insights and learning about how the initial artefacts have been reshaped by on-going use. These help to design guided intervention.

Using the ADER allowed for redesigning the artefact from the researchers point view i.e., outsiders' view. It has identified various contexts; the IT artefacts' role (less important) and organization's role (more important). In such contexts, ADER provides guided intervention to inscribe the artefact into the organizational contexts. For instance, ADER built bilateral networks between the DRR and UISCs to implement ICT networks in this service. Further, it helped with mobilizing ICT networks through incorporating the organizational actors. 
Notably, the staff are low paid thus without appropriate incentives it would be difficult to make the ICT networks sustainable. Akbar (pseudonym), a records bearer confessed, "My salary is insufficient for food and clothes for my four member family. Besides, I need to pay tuition for my two children studying at college". This reflects how he joined the vested interest networks for survival (note that not all staff are in this position and some quite 'well off').

\subsection{Formalization of Learning}

The ADER enabled learning for both the organization and the researchers. The organization realized that it needs to understand the role of staff, organizational networks and vested interest networks that reshape ICT networks. Further, guided intervention is significant for continuous redesign of the artefacts. Since, ADER develops situated learning; the A2I has replicated them into a neighbouring district of Shopnapur. Further, it disseminated ADER learning to the relevant actors through presentations, workshops and discussions.

Moreover, A2I has outlined ADER learning at its Annual Conference for the Deputy Commissioners' of the country with a view to implementing them countrywide. A2I is expecting to implement the ADER designed ICT networks at the end of 2012. Finally, A2I, the Ministry of Land and the Ministry of Law have been working on amending the legal infrastructures, the obstacles for ICT networks have been identified by ADER.

Furthermore, the study derives learning for the researchers that DR need to build artefacts in organizational contexts. Since typically the DR framework does not include organizational contexts, ADR provides significant opportunity to build artefacts within organizational contexts and redesign organizational intervention. Finally, the study illustrated that incorporating ethnographic perspectives within ADR has the potential to elicit complex underlying contexts of developing countries and aid in redesigning the artefacts.

\subsection{Thick Description}

It has been said that ethnography is by definition "thick description" (where "thin description" is the activity and "thick description" refers to the meaning behind it, as well as its symbolic importance in society [30]) integral to ADER as reflected in the findings derived from the study. Incorporating an ethnographic perspective give a distinct nature to ADR, bringing together its insiders' and outsiders' views, along with a number of tools. This allows ADER to elicit valuable insights and underlying contexts that make the findings more informative, objective and authentic. Further, thick description seeks to add value to the ADER findings for practitioners and disciplines. 


\section{Conclusion}

Applying ADER in land records service delivery in Bangladesh can show a significant impact through redesigning the on-going ICT project. Since, service delivery is a highly complex field in developing countries, using an ethnographic perspective helps the ADER team to elicit insights to understand the processes, actors and networks. Eliciting the ethnographic perspective is not always easy because it requires spending time in the field and having a high level of analytical skills. This ADER team exploits the advantages through putting practitioners and professional together.

Therefore, ADER can be seen as a potential research method for studying ICTs in developing countries where the usual quantitative and descriptive analyses are not sufficient to reach into the insights of the organizational contexts and contribute to addressing practitioners' problems.

Acknowledgement. The authors express their sincere thanks to three anonymous reviewers for their valuable comments and directions on the first draft of this paper.

\section{References}

1. Avgerou, C., Walsham, G. (eds.): Information Technology in Context: Studies from the Perspective of Developing Countries. Ashgate, London (2000)

2. Unwin, T.: Context: The place of information and communication technologies for development. In: Unwin, T. (ed.) ICT4D Information and Communication Technologies for Development, pp. 1-51. Cambridge University Press, Cambridge (2009), http: / / www.gg.rhul.ac.uk/ict4d/Chapter1.pdf (accessed June 15, 2012)

3. Heeks, R.: Policy Arena: Do Information Communication Technologies (ICTS) Contribute to Development? Journal of International Development 22, 625-640 (2010)

4. Walsham, G.: Interpretive case studies in IS research: nature and method. European Journal of Information Systems 4, 74-81 (1995)

5. Orlikowski, W.J.: The duality of technology: Rethinking the concept of technology in organizations. Organization Science 3, 398-427 (1992)

6. Avgerou, C., Madon, S.: Framing IS studies. London School of Economics and Political Sciences, London (2002)

7. Hevner, R., March, S.T., Park, J., Ram, S.: Design science in information systems research. MIS Quarterly 28(1), 75-105 (2004)

8. Baskerville, R.: Action research for information systems. In: AMCIS 1999 Proceedings, Paper 288 (1999)

9. Sein, M.K., Henfridsson, O., Purao, S., Rossi, M., Lindgren, R.: Action Design Research. MIS Quarterly 35(3), 37-56 (2011)

10. Moore, B.H.: Land Reform: From Failed Expectations to Renewed Opportunity. Land Agenda First 1, 2 (2008), http: / / www.alrd.org/pdf / enl/Newsletter\%201.pdf

11. Imran, A., Gregor, S.: Vested interests obstructing information systems use: Land administration in a least developed country in SIG GlobDev. In: Fourth Annual Workshop, Shanghai, China, December 3, pp. 1-24 (2011) 
12. Walsham, G.: Making a World of Difference: IT in a Global Context. John Wiley, Chichester (2001)

13. Sinha, S.: Computerisation of land records. Economic and Political Weekly 38(35), 3739$3740(2003)$

14. Acharya, R.B.: Adopting geo-ICT for land administration: Problems and solutions. Presented at 7th FIG Conference, Spatial Data Serving People: Land Governance and the Environment - Building the Capacity (2009)

15. Sahay, S., Avgerou, C.: Introducing the special issue on information and communication technologies in developing countries. Inf. Soc. 18(2), 73-76 (2002)

16. Thomas, P.: Bhoomi, Gyan Ganga, e-governance and the right to information: ICTs and development in India. Telematics Inf. 26(1), 20-31 (2009)

17. Hassard, J., Law, J., Lee, N.: Themed section: Actor-Network theory and managerialism. Organisational Studies 6, 385-390 (1999)

18. Atkinson, C.J., Brooks, L.S.: StructurANTion: A theoretical framework for integrating human and IS research and development. In: AMCIS 2003 Proceedings. Paper 378, pp. 2895-2902 (2003)

19. Law, J.: Notes on the theory of the Actor-Network: Ordering, strategy, and heterogeneity. Systems Practice 5, 379-393 (1992)

20. Latour, B.: Reassembling the Social: An Introduction to Actor-Network-Theory. Oxford University Press, Oxford (2005)

21. Callon, M.: Some elements of a sociology of translation: Domestication of the scallops and the fishermen of St Brieuc Bay. In: Law, J. (ed.) Power, Action and Belief: A New Sociology of Knowledge?, pp. 196-233. Routledge \& Kegan Paul, London (1986)

22. Silva, L.: Epistemological and theoretical challenges for studying power and politics in information systems. Information Systems Journal 17(2), 165-183 (2007)

23. Orlikowski, W.J., Iacono, C.S.: Research Commentary: Desperately Seeking the 'IT' in IT Research-A Call to Theorizing the IT Artifact. Information Systems Research 12(2), 121-134 (2001)

24. Gregor, S., Jones, D.: The anatomy of a design theory. Journal of the Association for Information Systems 8, 312-335 (2007)

25. Garud, R., Jain, S., Tuertscher, P.: Incomplete by design and designing for incompleteness. Organization Studies 29(3), 351-371 (2008)

26. van Aken, J.E.: Management research based on the paradigm of the design sciences: The quest for field-tested and grounded technological rules. Journal of Management Studies 41(2), 219-246 (2004)

27. Myers, M.D.: Investigating information systems with ethnographic research. Communications of the Association for Information Systems 2, 1-20 (1999)

28. Crabtree, M.R., Tolmie, P.: Doing Design Ethnography. Springer, London (2012)

29. Geertz: From the native's point of view: On the nature of anthropological understanding. In: Geertz, C. (ed.) Local Knowledge, pp. 55-70 (1983)

30. Geertz: Thick Description: Toward an Interpretive Theory of Culture. Basic Book Inc., New York (1973) 